\title{
Controlling Solar Radiation Is a Performance Indicator for a Solar Power Plant
}

\author{
Elhadj Ali Aoudou', Benoit Ndzana ${ }^{2}$ \\ ${ }^{1}$ Postgraduate School of Science, Technology and Geoscience, Research and Postgraduate Training Unit in Engineering and Its Applications, \\ University of Yaounde 1, Yaounde, Cameroon \\ ${ }^{2}$ Department of Electrical Engineering and Telecommunications, National Advance School of Engineering, Yaounde, Cameroon
}

Email address:

aliaoudou1952@yahoo.com (E. A. Aoudou), bendzana@gmail.com (B. Ndzana)

\section{To cite this article:}

Elhadj Ali Aoudou, Benoit Ndzana. Controlling Solar Radiation Is a Performance Indicator for a Solar Power Plant. American Journal of Science, Engineering and Technology. Vol. 5, No. 1, 2020, pp. 48-51. doi: 10.11648/j.ajset.20200501.16

Received: January 9, 2020; Accepted: March 6, 2020; Published: April 8, 2020

\begin{abstract}
Certain regions of Africa are classified as a zone rich in hydrocarbons. We are talking about the Maghreb area and the Gulf of Guinea. The countries most concerned are: Libya, Algeria, South Sudan, Nigeria, Congo Brazzaville, Angola, Gabon, Equatorial Guinea and many others are recognized as producers of oil, therefore supposedly rich in foreign currency. These countries find it difficult to cope with the problems of managing their poorly managed oil manna: they can lead their country to neglect the agriculture that has always fed Africa. It can be said that these countries did not develop their industries through this oil revenue. Others strongly assert that oil is a source of misfortune in Africa because the population does not benefit from these oil revenues. Today this population is facing global warming due to the greenhouse effect. World conferences recommend reducing $\mathrm{CO}_{2}$ emission. Some countries are said to be "polluters" and the concept "polluter pays" is accepted. Above all, finding a sickle fuel resource is a world-famous event; all the nations of the earth would like to be the owner of this discovery, but we know that today these resources are limited and even threatened with disappearance: some advance the time remaining between 30 and 100 years. The earth's fuel resources are running out day by day alongside ever-increasing global demand. The sharp rise in the price of oil in 1973 led the world to focus more and more on renewable energy sources, first and foremost solar energy. This one wants to be free and available on a large part of the terrestrial globe. When one tries to calculate the energy balances of a solar installation, it is often of the continual variation of solar radiation that the main problems are born. The mastery of the estimation of the sun leads us towards a study of the environmental climatology: the case of Cameroon, so that Controlling Solar Radiation is a Performance Indicator for a Solar Power Plant.
\end{abstract}

Keywords: Sickle Resources, Solar Energy Sunshine, Climatology, Environment

\section{Introduction}

On the environmental front there is global warming of the earth following the greenhouse effect. Global conferences recommend today the reduction of $\mathrm{CO}_{2}$ emissions by nations called "polluters" and the concept such as "polluters payers" has emerged. Today we advocate the production and use of renewable energy on a large scale to reduce these greenhouse effects around the world, many projects are underway. Renewable energies come from regular or constant natural phenomena caused by the stars, mainly the sun (radiation), but also the moon (tide) and the earth (geothermal energy). This research project aims to contribute to the analysis of sunshine calculation methods for a good performance evaluation in a solar plant installation project in Cameroon.

Our work will be argued around three chapters: in the first chapter: we will analyze the main climatic parameters of a sun in general and in Cameroon in particular. At the level of the second chapter: We will expose the mathematical models of certain elements such as the sensors, the incident solar flux and the ambient temperature. By the third chapter: we will offer the opportunity to make a discussion- validation and a conclusion of our work on the theme "The mastery of sunshine is an indicator of the performance for a solar power station". 


\section{The Main Climatic Parameters}

\subsection{Solar Radiation}

The sun emits several types of waves among which is the solar radiation which is of electromagnetic origin. This radiation constitutes $99.97 \%$ of the earth's heat sources. [2]

\subsubsection{The Characteristics of Solar Radiation}

Solar energy at ground level is available as electromagnetic radiation emitted from the sun.

The power transmitted by this radiation varies with the wavelength of the radiation. The greatest amount of energy is brought by visible waves (white light which is the superposition of all colors).

Some waves are absorbed partially or totally by the particles of the atmosphere (the ozone molecules absorb part of the ultraviolet) [3].

The incident power per unit area on a given plane is called irradiance. It is given in $\mathrm{W} / \mathrm{m}^{2}$. By integrating the irradiances over a given time interval, the irradiations, usually given in $\mathrm{kWh} / \mathrm{m}^{2}$, are accessed.

\subsubsection{Types of Solar Radiation}

There are four types of solar radiation global, direct, diffuse and reflected. In a given plane, the incident irradiation, called global irradiation, is the sum of three components (or two if the plane is horizontal):

i. Direct irradiation $\left(\mathrm{kWh} / \mathrm{m}^{2} / \mathrm{d}\right)$ : Comes directly from the sun. This component is zero when the sun is hidden by clouds or by an obstacle (building, distant mask).

ii. Diffuse irradiation $\left(\mathrm{kWh} / \mathrm{m}^{2} / \mathrm{d}\right)$ : Corresponds to radiation received from the celestial vault, excluding direct radiation.

iii. Reflected irradiation $\left(\mathrm{kWh} / \mathrm{m}^{2} / \mathrm{d}\right)$ : corresponds to the radiation returned by the soil and the environment. This component is zero on a horizontal plane.

The different types of solar radiation are shown in Figure 1.

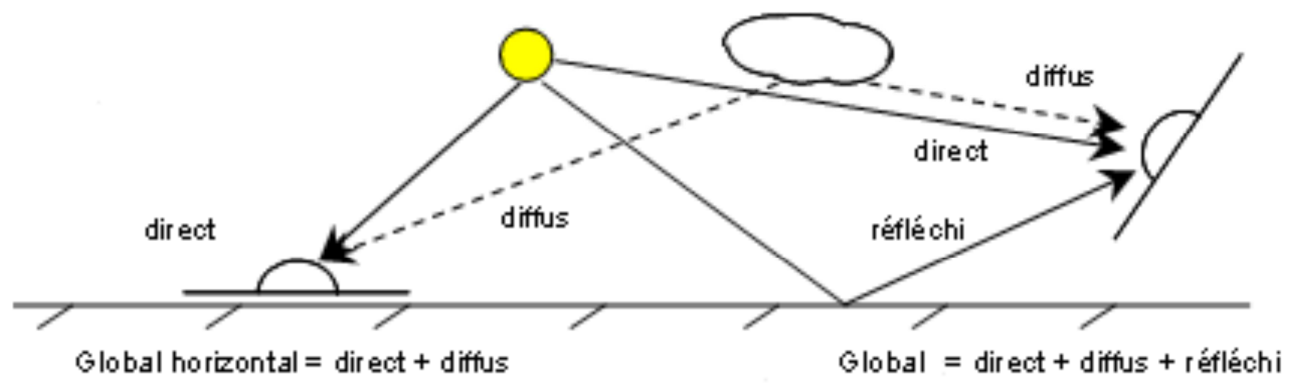

Figure 1. Types of solar radiation.

\subsection{Ambient Temperature}

The ambient temperature is the temperature of the environments. It is a term that can be applied outside or inside a place. The ambient temperature of a place may change depending on time as well as space. It depends on latitude and longitude, night or day and altitude.

The ambient temperature depends on the distance to the sun, measured in Astronomical Unit (AU): 1UA 150 million $\mathrm{km}$. This Astronomical Unit is the distance from the earth to the sun. It is equal to half of the major axis of the Earth's orbit. It is the unit that is adapted to the dimensions of solar systems.

There are two types of temperature [5]: the temperature in the shade and the temperature in the sun. The temperature is measured according to several scales, the most used are Kelvin, Celsius and Fahrenheit:

i. The Kelvin scale: represents the unit of temperature measurement in the international system. The degree 0 of the Kelvin scale, or absolute zero, corresponds to a total absence of microscopic agitation.

ii. The Celsius scale: this is the Kelvin scale to which is subtracted $273.15 \mathrm{~K}$.

iii. The Fahrenheit scale: It assigns a range of $180^{\circ} \mathrm{F}$ between the solidification temperature of the water and its boiling point. Thus, the degree Fahrenheit equals 5/9 of a degree Celsius where it sets the solidification point of water at $32^{\circ} \mathrm{F}$ (hence its boiling point at $212^{\circ} \mathrm{F}$ ). The equations connecting the different scales are:

$$
\begin{aligned}
& { }^{0} \mathrm{C}=\frac{5}{9}(0 \mathrm{~F}-32) \\
& { }^{0} \mathrm{C}={ }^{0} \mathrm{~K}-373.15
\end{aligned}
$$

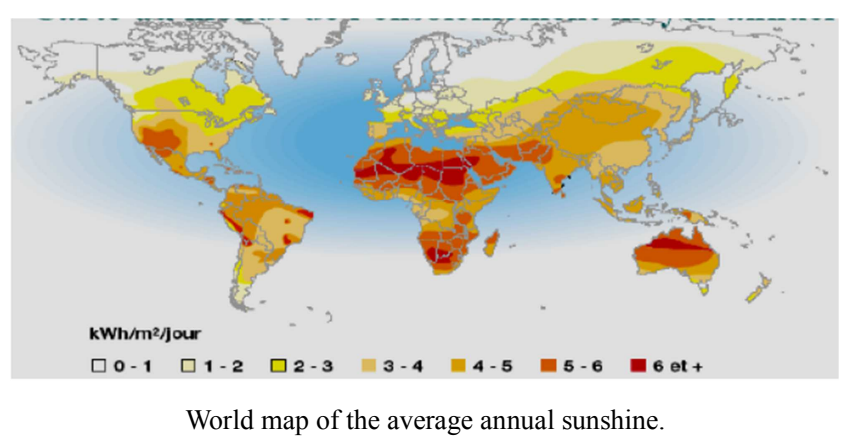

Figure 2. Carte du monde de l'ensoleillement moyen annuel.

\section{The Case of Cameroon}

Solar Radiation in Cameroon

The duration of insolation is measured using a Campbell heliograph. The principle of the device is simple: a sphere of massive glass often called "crystal ball" focuses the sun's rays on a strip of cardboard, thus causing a burn line whose length is proportional to the duration during which the sun 
was present. The measurement is expressed in hours and tenths.

i. The average monthly insolation times in N'Djamena, Maroua-Salak and Yaoundé are given in Figure 3 which can be interpreted as follows: The average annual duration of the presence of the sun is almost doubled in the north of the province in N'Djamena $(3.150 \mathrm{~h})$ from that observed at Yaoundé $(1.650 \mathrm{~h})$. In Maroua-Salak, an annual average of 2.900 hours is measured.

ii. In the Far North, every month (except August in Maroua) has a value greater than the monthly maximum of Yaoundé (178 hours in January).

iii. Concerning the monthly distribution, we naturally have a minimum during the rainy season (August) and a maximum during the dry season (December).

iv. Concerning the monthly distribution, we naturally have a minimum during the rainy season (August) and a maximum during the dry season (December).

v. For a reason that escapes us (due to the data retained), The resumption of sunstroke observed in May both in N'Djamena and Yaoundé, is not visible in Maroua.

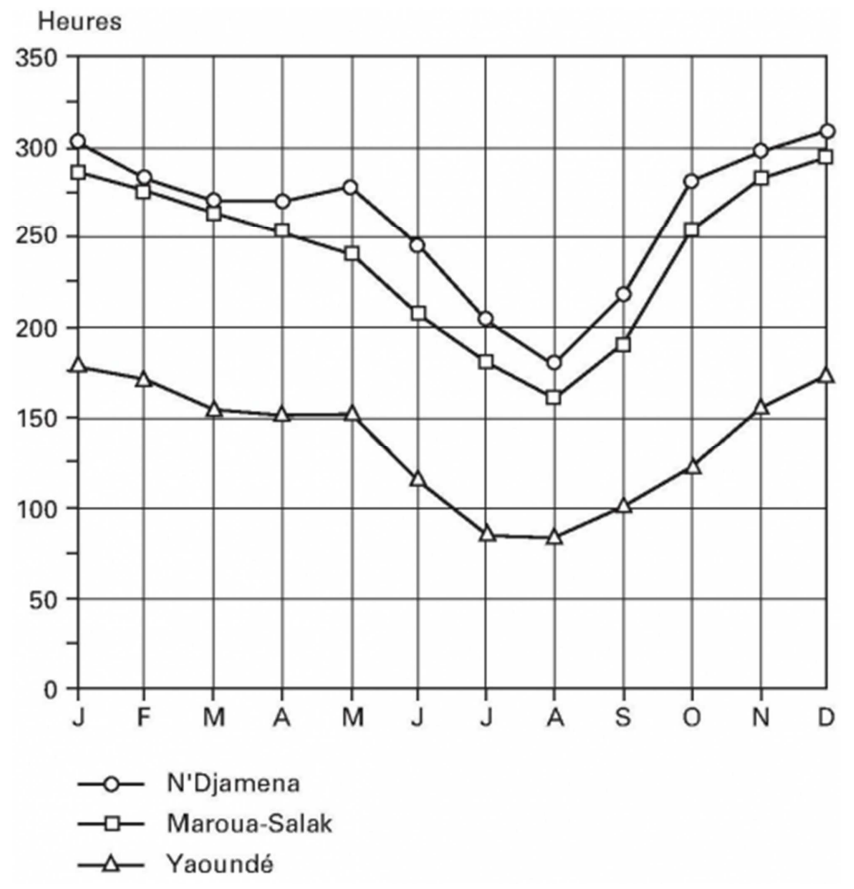

Figure 3. Monthly averages of insolation times (in hours).

The results are shown in the table below:

The first column of this table, called "Ed", gives the average energy output per day for a 1 kilowatt-peak installed. For example, here, a installation of $1 \mathrm{kWc}$ will produce an average of $3.40 \mathrm{kWh}$ in July (which is the worst month of the year) and $4.57 \mathrm{kWh}$ in February (the best month). The average production over the year will be $4.06 \mathrm{kWh}$.

Table 1. Annual production of sunstroke in Cameroon.

\begin{tabular}{|c|c|c|c|c|}
\hline \multicolumn{5}{|c|}{ Fixed system: inclination $=6$, Orientation $=-4$ (optimum) } \\
\hline Month & $\mathbf{E}_{\mathbf{d}}$ & $\mathbf{E}_{\mathbf{m}}$ & $\mathbf{H}_{\mathrm{d}}$ & $\mathbf{H}_{\mathrm{m}}$ \\
\hline Jan & 4.47 & 139 & 6.25 & 194 \\
\hline
\end{tabular}

\begin{tabular}{lllll}
\hline \multicolumn{5}{l}{ Fixed system: inclination=6, Orientation=-4 } \\
\hline Month & $\mathbf{E}_{\mathbf{d}}$ & $\mathbf{E}_{\mathbf{m}}$ & $\mathbf{H}_{\mathbf{d}}$ & $\mathbf{H}_{\mathbf{m}}$ \\
\hline Feb & 4.57 & 128 & 6.43 & 180 \\
Mar & 4.52 & 140 & 6.33 & 196 \\
Apr & 4.20 & 126 & 5.83 & 175 \\
May & 4.01 & 124 & 5.53 & 172 \\
Jun & 3.60 & 108 & 4.92 & 148 \\
Jul & 3.40 & 105 & 4.65 & 144 \\
Aug & 3.61 & 112 & 4.95 & 153 \\
Sep & 3.96 & 119 & 5.42 & 163 \\
Oct & 3.82 & 118 & 5.26 & 163 \\
Nov & 4.22 & 127 & 5.83 & 175 \\
Dec & 4.22 & 137 & 6.15 & 191 \\
Yearly average & 4.06 & 124 & 5.63 & 171 \\
Total for year & 1480 & & 2050 & \\
\hline
\end{tabular}

http://energie-developpement.blogspot.com/2011/09/solaire-logiciel-gratuitpour-evaluer.html.

\section{The Mathematical Modeling of the Sensors, the Incident Solar Flux and the Ambient Temperature}

About mathematical models of solar flux: there are several mathematical models for estimating the solar flux based on different climatic parameters; we present some of them.

Different Parameters of the Solar Flux [2]

In what follows we define the main parameters needed to calculate the incident solar flux on a point of our planet

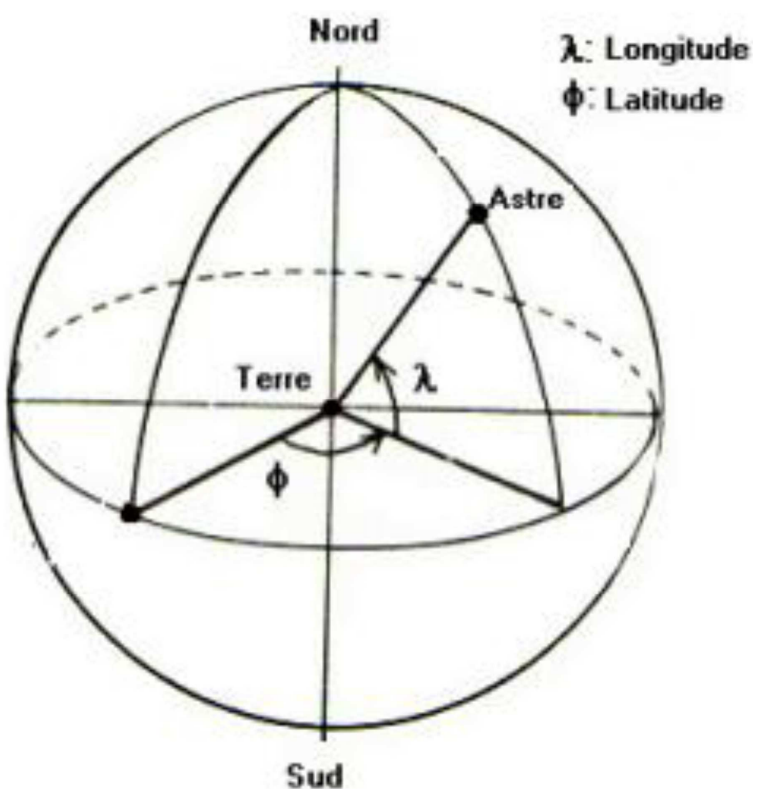

Figure 4. Geographic Coordinates.

(1) Latitude

One of the terrestrial coordinates of a point of our planet. This is the angle that the plane of the equator makes with the direction connecting the center of the earth to the point considered. noted $(\varnothing)$, its value is positive in the northern hemisphere, and negative in the southern hemisphere.

(2) Longitude 
One of the terrestrial coordinates of a point of our planet. This is the angle of the local meridian passing through the point considered with the original meridian

passing through the city of Greenwich. Noted (L), its value is positive in the west and negative in the east of the meridian origin.

\section{(3) Hour Angle}

The hour angle of the sun, noted is the angle formed by the meridian plane of the place and that which passes by the direction of the sun. To calculate it we need to know the following parameters:

i. Equation of time (Et) given by:

$$
E t=0.0002+0.4190 \cos d(j)-7.3509 \sin d(j)-3.2265 \cos d(2 j)-9.3912 \sin d(2 j)-0.0903 \cos d(3 j)-0.3361 \sin d(3 j)(3)
$$

Where $\mathrm{j}=360 \frac{q}{366}$ et $\mathrm{q}$ : Number of the day since January $1^{\text {st }}$

ii. Average solar time (TSM):

$$
\mathrm{TSM}=\mathrm{TU}-\mathrm{Lo} / 15
$$

Where is the Universal Time (or GMT) and Lo is the longitude of the place. [2]

iii. True solar time (TSV):

$$
\mathrm{TSV}=\mathrm{TSM}+\mathrm{Et} / 60
$$

So the hour angle is given by the following formula:

$$
\omega=15(\mathrm{TSV}-12)
$$

iv. Coefficient of correction of the Earth-Sun distance

$$
\alpha=1+0.034 \cdot \cos \left(360 \cdot \frac{q}{366}\right)
$$

v. Declination of the sun

The axis of rotation of the earth is inclined relative to the plane of the ecliptic (plane in which the Earth moves around the sun) The declination is the angle between the plane of the equator and the direction earth - sun. It varies between $23^{\circ}$ 27 'at the summer solstice and $-23^{\circ} 27^{\prime}$ at the winter solstice, in a sinusoidal way.

The inclination of the axis of the earth makes it possible to explain the apparent trajectory of the sun in the sky. Approximate formulas allow the calculation of the declination at day q of the year:

$$
\delta=+23.45 . \operatorname{Sin}\left(360 \cdot \frac{(234+q)}{(365)}\right)
$$

With q: Number of the day since January 1 st. vi. Sun height and azimuth

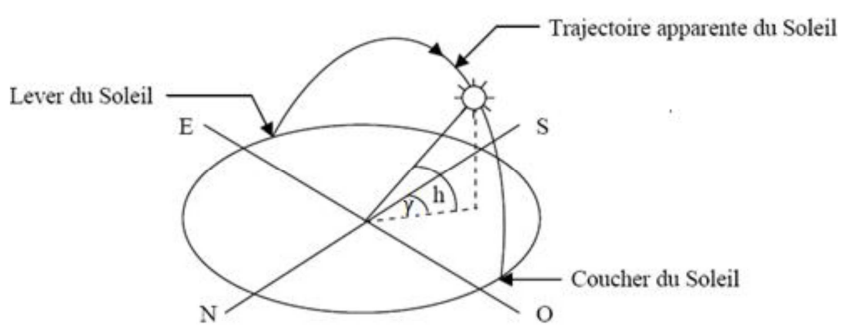

Figure 5. Spotting the sun.

To locate the position of the sun in the sky, two angles are used: (See Figure 5)

1. The height h: Angle between the direction of the sun and its projection on the horizontal plane.

2. The azimuth $\gamma$ : Angle between this projection and the direction of the South: $\gamma$ is counted positively towards the West and negatively towards the East.

Approximate formulas allow the calculation of the height of the sun, the azimuth and the trajectory of the sun:

$$
\begin{gathered}
\operatorname{Sin} \mathrm{h}=\sin \varphi \sin \delta+\cos \varphi \cos \delta \cos \omega \\
\sin \gamma=\frac{\cos \delta \sin \omega}{\cosh }
\end{gathered}
$$

The trajectory of the sun is given by the following expression:

$$
\mathrm{AM}=\frac{(1-0,1 \text { alt })}{\sin \mathrm{h}}
$$

(With alt: The altitude of the place.

i. Angle of incidence

It is the angle formed by the direction of the solar rays with the considered surface of capture, whose expression is the following one:

$\cos \theta i=\sin \varphi \sin \delta \cos i-\sin \varphi \cos \delta \sin i \sin o+\cos \delta \cos \varphi \cos i$ $\cos \omega+\cos \delta \sin \varphi \sin i \cos o \cos \omega+\cos \delta \sin i \sin o \sin \omega(12)$

With:

o: Angle of orientation of the solar collector. It is zero when the surface is facing south, positive for eastward and negative for westward.

ii. Angle of inclination of the solar collector.

iii. Maximum duration of sunshine $\nabla \mathrm{TO}$

It corresponds to the duration of sunshine of the day for a given place, its formula is given by the following relation:

$$
\nabla T O=\frac{2}{15} \cdot \operatorname{arcos}(-\tan \varphi \cdot \tan \delta)
$$

Where $\varphi$ is the latitude and $\delta$ the declination of the sun iv. Coefficient of atmospheric disorder $\beta$

This coefficient can be estimated according to the coefficients TO, $\mathrm{u}, \mathrm{v}$ available by climatic zone of the period of the year.

$$
\beta=\mathrm{TO}+\mathrm{u} \times \cos (0.986, \mathrm{q})+\mathrm{v} \times \sin (0.986 \times \mathrm{q})
$$

With q: Number of the day since January 1st.

Table 2. Values of the coefficients TO, $u$ and $v$.

\begin{tabular}{llll}
\hline Zone & TO & u & v \\
\hline Méditerranéenne: cote & 3.25 & -1.1 & -0.15 \\
Intérieur & 3.15 & -0.5 & -0.05 \\
Atlantique & 3.25 & -0.7 & -0.15 \\
Continentale & 3.75 & -0.2 & -0.05 \\
Grandes agglomérations & 4.05 & -0.5 & -0.1 \\
\hline
\end{tabular}


v. The tilt of the sensor [2]

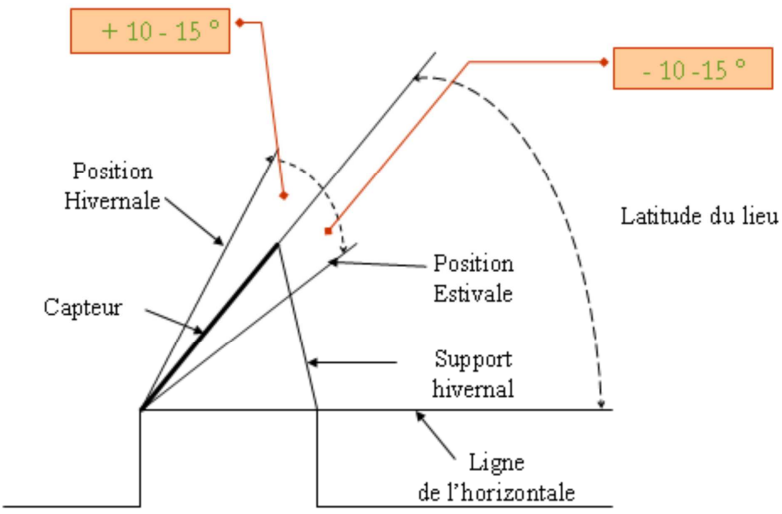

Figure 6. Orientation of solar sensors.

The solar collectors may be installed on the ground, against the side of a building or on the roof, facing south, away from shaded areas, and which should have an angle of inclination so that the surface of capture is perpendicular to solar radiation. The calculation of the angle of inclination is done by subtracting the declination of the sun from the geographical latitude of the location of the location of the solar collector. In general, this is the latitude of the location plus or minus 10 to 15 degrees. In winter (winter position), when the path of the sun is low in the sky, a higher angle of inclination (latitude plus 10 to 15 degrees) must be used. It is recommended to use a lower angle of inclination (latitude minus 10 to 15 degrees) during the summer months when the sun is higher in the sky (summer position). (See Figure 6)

vi. Albedo soil

The albedo of the soil, noted, is the reflection coefficient of the solar radiation by the ground, it depends on the nature of the latter as follows:

$$
\rho=\begin{gathered}
0.2 \text { to } 0.4 \text { greenery } \\
0.4 \text { to } 0.8 \text { clear soil } \\
0.8 \text { to } 0.9 \text { snow }
\end{gathered}
$$

vii. Modeling the ambient temperature

Ambient temperature is a parameter that significantly affects the performance of a solar collector, so it is essential to know its evolution throughout the day studied. It is estimated by the following formula:

$$
\mathrm{Ta}(\mathrm{m}, \mathrm{t})=\frac{\operatorname{Tmax}(m)+T \min (m)}{2}+\frac{\operatorname{Tmax}(m)-T \min (m)}{2} \cdot \sin \left(\pi \frac{(t-1)}{12}\right)
$$

The latter returns to the environment temperature at the time of the day. It is calculated as a function of $\mathrm{T} \min (\mathrm{m})$ and $\mathrm{T}$ max $(\mathrm{m})$, the minimum daily and minimum 24-hour temperatures are obtained from the National Office.

Meteorology (O. N. M). They are recorded from

\begin{tabular}{|c|c|c|c|c|c|c|c|c|c|c|c|c|}
\hline Mois & 1 & 2 & 3 & 4 & 5 & 6 & 7 & 8 & 9 & 10 & 11 & 12 \\
\hline Température maximale $\left({ }^{\circ} \mathrm{C}\right)$ & 16.7 & 17.4 & 19.2 & 20.9 & 23.9 & 28.2 & 31.2 & 32.2 & 29.6 & 25.9 & 20.8 & 17.9 \\
\hline Température minimale $\left({ }^{\circ} \mathrm{C}\right)$ & 5.5 & 5.9 & 7.1 & 8.8 & 12.3 & 16.1 & 18.9 & 19.8 & 17.6 & 14.2 & 9.8 & 7.2 \\
\hline
\end{tabular}
measurements collected over 30 years. For the city of Algiers (See Table 3). [2]

Table 3. Monthly Daily Average Temperatures.

\section{(4) Different Mathematical Models of Sunshine}

The study of sunshine is the basis of any estimate of an application using solar energy. There are several models for estimating sunshine proposed in the literature by various researchers. We present the most used models.

i. Model of EUFRAT [2]

This model, which allows the calculation of energetic lightening's, makes use of the atmospheric disorder through the coefficient of atmospheric disorder $\beta$.

After calculating all the climatic parameters, we proceed to calculate the different types of radiation:

1. Direct radiation at normal incidence: In (in $\mathrm{W} / \mathrm{m}^{2}$ )

$$
\mathrm{I}_{\mathrm{n}}=\mathrm{I}_{0} \cdot \alpha \cdot \exp \left[\frac{-A M \cdot \beta}{0.9 A M+9.4}\right]
$$

Where: - $\mathrm{I} 0=1367 \mathrm{~W} / \mathrm{m}^{2}$. (Solar constant)

$\alpha$ is the correction coefficient of the Earth-Sun distance.

$\mathrm{AM}$ is the path of the sun.

2. Global horizontal radiation: $\mathrm{Gh}$ (in $\mathrm{W} / \mathrm{m}^{2}$ )

$$
\mathrm{G}_{\mathrm{h}}=\alpha \cdot(1270-56 \cdot \beta) \cdot \sin (\mathrm{h}) \frac{\beta+36}{33}
$$

Where $h$ is the height of the sun. Diffuse horizontal radiation: $\mathrm{Dh}$ (in $\mathrm{W} / \mathrm{m}^{2}$ )

$$
\mathrm{D}_{\mathrm{h}}=\mathrm{G}_{\mathrm{h}}-\mathrm{I} \sin \mathrm{h}
$$

For the calculation of the global radiation on the inclined planes, we have the following formulas:

3. Diffuse radiation on an inclined plane: $\mathrm{Di}$ (in $\mathrm{W} / \mathrm{m}^{2}$ )

$$
\begin{gathered}
\text { If } \frac{\theta i}{\sinh }>\mathrm{C}_{\mathrm{p}} \text { then } \mathrm{D}_{\mathrm{i}}=\mathrm{D}_{\mathrm{h}}\left(\mathrm{F}_{2} \cdot \mathrm{C}_{\mathrm{p}}+\frac{(1-F 2) \cdot \theta i}{\sinh }\right) \\
\text { If } \frac{\theta i}{\sinh } \leq \mathrm{C}_{\mathrm{p}} \text { then } \mathrm{D}_{\mathrm{i}}=\mathrm{D}_{\mathrm{h}} \cdot \mathrm{C}_{\mathrm{p}}
\end{gathered}
$$

Where is the angle of incidence?

With F2 and Cp are given by the following expressions:

$$
\begin{gathered}
\mathrm{F} 2=1-\frac{I n}{I 0} \alpha \\
\mathrm{C}_{\mathrm{p}}=\frac{1+\cos i}{2}
\end{gathered}
$$

4. Global radiation on an inclined plane: $\mathrm{Gi}$ (in $\mathrm{W} / \mathrm{m}^{2}$ )

$$
\mathrm{G}_{\mathrm{i}}=\mathrm{I}_{\mathrm{n}} \cdot \cos \theta_{\mathrm{i}}+0.2 \mathrm{D}_{\mathrm{i}} \cdot \text { Dh. } \frac{1-\cos i)}{2}
$$

Where $\mathrm{i}$ is the inclination of the sensor.

ii. Model of Brichambaut Perrin [2]

Theoretically solar radiation can be estimated by the model that employs the total disorder factor of Linke T.

The definition of the disturbance factor uses several hypotheses that require knowledge of many climatic 
parameters.

The cloud factor is considered based on the local climatic characteristics of the site and the height of the sun, defined as the sum of the three auxiliary disturbance factors. The cloudiness factor (clear sky) is broken down into 03 auxiliary disorders factors, T1, T2 and T3:

With $\mathrm{T} 1, \mathrm{~T} 2$ and $\mathrm{T} 3$ are given by the following expressions:

$$
\begin{aligned}
& \mathrm{T} 1=2,4-0,9 \sin (\varphi)+0,1(2 \sin \varphi . \text { Ah }-0,2 \text { alt }-(1,22+0,14 . \text { Ah }) .(1-\sin \mathrm{h}) \\
& \mathrm{T} 2=(0,89) \text { alt } \\
& \mathrm{T} 3=(0,9+0,4 . \mathrm{Ah}) .(0,63) \\
& \mathrm{a}=\log \mathrm{T}^{\prime}-3.1-\log (\sin \mathrm{h}) \\
& \mathrm{b}=\exp (-0.2+1.75 \cdot \log (\sinh ))
\end{aligned}
$$

Altitude of the place:

Where Ah is given by the following relation:

q: Number of the day from January 1 st.

Direct radiation is given by: For any reception plane, the power of the incident direct radiation is expressed by:

Knowing that on a horizontal plane we have: therefore, the preceding relation becomes:

Where the term radiation outside the atmosphere is expressed by the relation:

$$
\text { Gne }=\left(1+0.0334 \cdot \cos \left(\frac{360}{365} q-2\right)\right) .1353
$$

Diffuse radiation (d) is composed of three parts:

$$
\mathrm{d}=\mathrm{d}_{1}+\mathrm{d}_{2}+\mathrm{d}_{3}
$$

Diffuse radiation from the sky $(\mathrm{d} 1)$

$$
\mathrm{d} 1=\delta_{\mathrm{d}} \cos \theta_{\mathrm{i}}+\frac{1+\sin \gamma}{2}+\delta_{\mathrm{h}} \cdot \cos \gamma
$$

Where the direct component $\mathrm{d}$ is expressed by:

$$
\delta_{\mathrm{d}}=\text { gne. } \exp (-2.48+\sin \mathrm{h}+\mathrm{a}-\sqrt{b 2+a 2})
$$

With: $a=3.1-0.4 b$ And

$$
b^{\prime}=\log T^{\prime}-2.28-0.50 . \log (\sin h)
$$

whereas

$$
\mathrm{T}^{\prime}=\mathrm{T}_{1}+\mathrm{T}_{2}
$$

The isotropic component that corresponds to a sky of uniform luminance is given by:

On the other hand, corresponds to the circle of the horizon and is given by the expression:

$$
\delta_{\mathrm{i}}=\mathrm{d}_{\mathrm{h}}-\delta_{\mathrm{h}} \cdot \sinh
$$

with

$$
\mathrm{d}_{\mathrm{h}}=\text { gne. } \operatorname{Exp}-1+1.06 \cdot \log (\sin \mathrm{h})+\mathrm{a}-\sqrt{\mathrm{b} 2 \mathrm{a} 2}
$$

Such as

$$
\mathrm{B}=\log \mathrm{T}^{\prime}-2.8+1.02 .(1-\sin \mathrm{h})^{2}
$$

And $\alpha=1.1$

On the other hand, corresponds to the circle of the horizon and is given by the expression:

$$
\delta_{\mathrm{h}}=\text { gne. } \frac{-0.02 a}{\mathrm{a} 2+\mathrm{a} \cdot \mathrm{b}+1.8} \cdot \exp (\sin \mathrm{h})
$$

Diffuse radiation from the soil (d2), is expressed by the relation:

$$
\mathrm{d}_{2}=\delta_{\mathrm{a}} \frac{1-\sin \gamma}{2}
$$

whereas

$$
\delta_{\mathrm{a}}=\rho\left(\mathrm{S}_{\mathrm{n}}+\mathrm{d}_{\mathrm{n}}\right)
$$

Diffuse retro-radiation (d3) is given as follows:

$$
\mathrm{d}_{3}=\delta_{\mathrm{r}} \frac{1+\sin \gamma}{2}
$$

Where the term is given by:

$$
\delta_{\mathrm{r}}=0.9 \cdot(\rho-0.2) \cdot\left(\mathrm{S}_{\mathrm{n}}+\mathrm{d}_{\mathrm{n}}\right) \cdot \exp \left(\frac{-4}{\sqrt{T} \prime}\right)
$$

The global radiation incident at a given instant, on any plane is therefore given by the sum of two terms:

$$
\mathrm{G}=\mathrm{S}+\mathrm{d}
$$

iii. Model Liu Jordan [2]

In practice it is more convenient to estimate global illumination on an inclined plane by the generalized LIU JORDAN relation in the form

$$
G=\mathrm{S}_{\mathrm{h}} \cdot \mathrm{R}_{\mathrm{b}}+\mathrm{d}_{\mathrm{n}}\left(\frac{1+\cos i}{2}\right)+\left(S_{h}+\mathrm{d}_{\mathrm{h}}\right) \cdot\left(\rho \frac{1-\cos i}{2}\right)
$$

Direct irradiation on an inclined plane is expressed by the following relation:

$$
\mathrm{Si}=\mathrm{S}_{\mathrm{n}} \cdot \mathrm{R}_{\mathrm{b}}
$$

Where, the inclination factor $\mathrm{Rb}$ of the direct radiation is:

$$
\mathrm{Rb}=\frac{\cos (\varphi-i) \cdot \cos \delta \cdot \cos \omega+\sin (\varphi-i) \cdot \sin \delta}{\cos \varphi \cdot \cos \omega+\sin \varphi \cdot \sin \delta}
$$

Diffuse irradiation on an inclined plane is:

$$
\mathrm{d}_{\mathrm{i}}=\mathrm{d}_{\mathrm{n}}\left(\frac{1+\cos i}{2}\right)
$$

on the other hand irradiation reflected on an inclined plane is estimated by the expression:

$$
\mathrm{d}_{\mathrm{ri}}=\left(\mathrm{s}_{\mathrm{h}}+\mathrm{d}_{\mathrm{n}}\right) \cdot\left(\frac{1-\cos i}{2}\right) \cdot \rho
$$

The two components of global solar radiation on a 
horizontal plane are estimated as follows:

Direct radiation

$$
\mathrm{Sh}=\mathrm{A} \cdot \sinh \cdot \exp \left(\frac{-1}{c \cdot \sin (h+2)}\right)
$$

Diffuse radiation

Where $\mathrm{A}, \mathrm{B}$ and $\mathrm{C}$ are constants which take into account the nature of the sky, are given according to the following table:

$$
\mathrm{dn}=\mathrm{B} .(\sinh )^{0.4}
$$

Table 4. Values of the coefficients $A, B$ and $C$.

\begin{tabular}{llll}
\hline Sky nature & A & B & C \\
\hline Sky very clear & 1300 & 87 & 6 \\
Sky medium & 1230 & 125 & 4 \\
Polluted sky & 1200 & 187 & 5 \\
\hline
\end{tabular}

\section{Discussing and Validation: General Conclusion}

\subsection{Discussion and Validation}

Problem posed by the estimation of the solar flux received by the sensors:

When one tries to calculate the energy balances of a solar installation, it is often of the continual variation of solar radiation that the main problems are born. Indeed, the analysis of the behavior of the solar collectors, or of the system with which they are associated, makes it possible to highlight different operating modes which depend on the incident solar power, the transition from one regime to another being done according to whether or not the received radiation exceeds certain critical values called threshold radiation.

When the intensity of sunshine varies a lot, as is generally the case, the whole system frequently changes its operating regime. Under these conditions, it is not possible to determine a priori average behavior of the entire installation that would serve to sizing.

To calculate the energy balances of a solar installation, it is therefore necessary to have as much information as possible on the distribution of incident solar power. Thus, one of the first difficulties that must be solved is to be able to correctly estimate the sunshine received by the solar collectors.

Within the framework of the calculation of the yield of a cylindro-parabolic solar system object of our thesis, it would be interesting to take into account the theoretical values with those of the manufacturers: These are the values obtained by mathematical modelling and the values resulting from manufacturers' labelling. But considering the constraints of the control of the sun which varies continuously, we opted for a global approach which takes into account all the factors coming into play in our designed solar system.

As, all the powers involved in the operation are calculated, we can proceed to a modeling of the yield.

\subsection{TVS-CP System Performance Modeling}

During the design of the parabolic solar power plant, we modulated the power input and output of the turbine where we calculated Power input turbine equal to $1.823778 \mathrm{MW}$ and by assumption we have: Power input turbine/Power output collector is equal to 1 therefore Power input turbine=Power output sensor $=1.823778 \mathrm{MW}$.

The designed solar power plant has at its input a power supplied by the sensor $(1.823778 \mathrm{MW})$ and at its output a power supplied by the rotor of the alternator (1.4MW).

In thermodynamics we have:

$$
\eta=\frac{\text { Power output }}{\text { Power input }}(\eta \text { is the efficiency of the system) }
$$

Digital Application:

$$
\eta=\frac{1.4 \mathrm{MW}}{1.823778 \mathrm{MW}}=0.76 \text { so } \eta=76 \%
$$

The system efficiency is:

$$
\eta=76 \%
$$

\subsection{As Conclusion}

To get a good assessment of the performance of a solar thermal installation, it is essential to master the climatology of your environment so that the solar flux received by the collector is known: daily, monthly and annually. The data recorded will allow mathematically to model its performance.

Within the framework of the calculation of the yield of a cylindro-parabolic solar system object of our thesis, it would be interesting to take into account the theoretical values and also those indicated by the manufacturers of solar materials: We are referring to the values obtained by mathematical modelling and the values displayed by manufacturer labelling. But considering the constraints of the control of the sun which varies continuously, we opted for a global approach which takes into account all the factors coming into action in our designed solar system.

Finally, as recommendations, we want those responsible for the Ministry of Higher Education to help the creation of laboratories dedicated to research work in the field of solar energy within the polytechnics Schools of Cameroon.

\section{References}

[1] Exploiting Sun's Energy Effectively as a Source of Renewable Energy, Deepa Khushalani www.researchgate.net , publication > 324913787_.

[2] Modélisation Mathématique et Simulation de Capteurs Solaires Yaici, Malika; promotrice; Iberraken, Aghiles; Alili, Riad: www.univ-bejaia.dz/dspace/handle/123456789/9241.

[3] Experimental monitoring of the performance of a photovoltaic solar power plant in Djibouti www.researchgate.net/publication/281992390.

[4] Thomas Fasquelle Modeling and experimental characterization of a cylindrical-parabolic solar loop incorporating thermocline-type storage. Other. University of Perpignan, 2017. Français. 
[5] Estimating the Potential of Concentrated Thermodynamic Solar Technology in Non-Desert Climate - Application à La Réunion: By Emeric TAPACHÈS.

[6] The Concentrating Solar Power Plants. University of Liège Faculty of Applied Sciences, Quoilin Sylvain https://fr.calameo.com/books/000419771243d279a6bd9.

[7] Direct steam generation in parabolic trough collectors M. Alguacila, C. Prietoa, A. Rodrigueza, J. Lohra a Abengoa Solar. Calle Energía Solar, 1, Sevilla 41014, Spain.

[8] Renewable and Sustainable energy Review in India Recent developments of solar energy in India: Perspectives, strategies and future egoals Subhojit Dawnn, Prashant Kumar Tiwari, Arup Kumar Goswami, Manash Kumar Mishra.

[9] SOLAR CONCENTRATION PLANT FOR RURAL ENVIRONMENT IN NIGER: STUDY OF THE CONCENTRATOR AND ECONOMIC AND ENVIRONMENTAL ASPECTS International Institute of Engineering Rue de la Science - 01 BP 594 - Ouagadougou 01 - BURKINA FASO - Mail: 2ie@2ie-edu.org-www.2ie.

[10] Siemens.com / energy / steam turbines: Pre-designed steam turbines; A full range of world-class industrial steam turbines.
[11] Kennedy, J., Eberhart, R., Shi, Y., Swarm Intelligence, 2001, Academic Press, Inc.

[12] S. Safari, M. M. Ardehali, M. J. Sirizi "Particle swarm optimization based fuzzy logic controller for autonomous green power energy system with hydrogen storage" Global Conference on Renewable energy and Energy Efficiency for Desert Regions 2011. "GCREEDER 2011", Energy Conversion and Management, Volume 65, January 2013, Pages 41-49.

[13] Randy L. Haupt, Sue Ellen Haupt" Practical Genetic Algorithms" second edition, 1998.

[14] Seth B. Darling, Fengqi You, Thomas Veselka, and Alfonso Velosa "Assumptions and the Levelized Cost of Energy for Photovoltaics", Created using the RSC ARTICLE templates (VER. 3.1).

[15] IRENA Working Paper, "RENEWABLE ENERGY TECHNOLOGIES: COST ANALYSIS SERIES", Volume 1: r. Power Sector, Issue 4/5 Solar Photovoltaics, June 2012.

[16] Bogdan S. Borowy Ziyad M. Salameh "Methodology for Optimally Sizing the Combination of a Battery Bank and PV Array in a Wind/PV Hybrid" IEEE Transactions on Energy Conversion, Vol. 11, No. 2, June 1996. 